\title{
Magnetic resonance spectroscopy of paragangliomas: new insights into in vivo metabolomics
}

\author{
Arthur Varoquaux ${ }^{1}$, Yann le Fur ${ }^{2}$, Alessio Imperiale ${ }^{3,4}$, Antony Reyre', \\ Marion Montava ${ }^{5}$, Nicolas Fakhry ${ }^{6}$, Izzie-Jacques Namer ${ }^{3,4}$, Guy Moulin', Karel Pacak ${ }^{7}$, \\ Maxime Guye ${ }^{1,2}$ and David Taïeb ${ }^{8,9,10}$ \\ 'Department of Medical Imaging, La Timone University Hospital, Aix-Marseille University, Marseille, France \\ ${ }^{2}$ CNRS, CRMBM UMR 7339, Aix-Marseille University, 13385 Marseille, France \\ ${ }^{3}$ Department of Biophysics and Nuclear Medicine, University Hospitals of Strasbourg, Strasbourg, France \\ ${ }^{4}$ ICube, UMR 7357, Faculty of Medicine, University of Strasbourg/CNRS and FMTS, Strasbourg, France \\ ${ }^{5}$ Department of Otorhinolaryngology-Head and Neck Surgery, North Hospital, Aix-Marseille University, \\ Marseille, France \\ ${ }^{6}$ Department of Otorhinolaryngology-Head and Neck Surgery, La Timone University Hospital, Aix-Marseille \\ University, Marseille, France \\ ${ }^{7}$ Program in Reproductive and Adult Endocrinology, Eunice Kennedy Shriver National Institute of Child Health and \\ Human Development (NICHD), National Institutes of Health, Bethesda, Maryland 20892, USA \\ ${ }^{8}$ Department of Nuclear Medicine, La Timone University Hospital, Aix-Marseille University, Marseille, France \\ ${ }^{9}$ Biophysics and Nuclear Medicine, European Center for Research in Medical Imaging, La Timone University Hospital, \\ Aix-Marseille University, 264, Rue Saint-Pierre, 13385 Marseille, France \\ ${ }^{10}$ INSERM, UMR1068, Institut Paoli-Calmettes, Marseille Cancerology Research Center, Marseille, France
}

Correspondence should be addressed to $\mathrm{D}$ Taïeb or A Varoquaux Emails

david.taieb@ap-hm.fr or DamienArthur. VAROQUAUX@ap-hm.fr

\begin{abstract}
Paragangliomas (PGLs) can be associated with mutations in genes of the tricarboxylic acid (TCA) cycle. Succinate dehydrogenase (SDHx) mutations are the prime examples of genetically determined TCA cycle defects with accumulation of succinate. Succinate, which acts as an oncometabolite, can be detected by ex vivo metabolomics approaches. The aim of this study was to evaluate the potential role of proton magnetic resonance (MR) spectroscopy ( $\left.{ }^{1} \mathrm{H}-\mathrm{MRS}\right)$ for identifying SDHx-related PGLs in vivo and noninvasively. Eight patients were prospectively evaluated with single voxel ${ }^{1} \mathrm{H}$-MRS. MR spectra from eight tumors (four SDHx-related PGLs, two sporadic PGLs, one cervical schwannoma, and one cervical neurofibroma) were acquired and interpreted qualitatively. Compared to other tumors, a succinate resonance peak was detected only in $S D H x$-related tumor patients. Spectra quality was considered good in three cases, medium in two cases, poor in two cases, and uninterpretable in the latter case. Smaller lesions had lower spectra quality compared to larger lesions. Jugular PGLs also exhibited a poorer spectra quality compared to other locations. ${ }^{1} \mathrm{H}-\mathrm{MRS}$ has always been challenging in terms of its technical requisites. This is even more true for the evaluation of head and neck tumors. However, ${ }^{1} \mathrm{H}$-MRS might be added to the classical MR sequences for metabolomic characterization of PGLs. In vivo detection of succinate might guide genetic testing, characterize $S D H x$ variants of unknown significance (in the absence of available tumor sample) , and even optimize a selection of appropriate therapies.
\end{abstract}

Key Words

- MR-spectroscopy

- paraganglioma

- positron-emission tomography

- metabolomics http://erc.endocrinology-journals.org DOI: 10.1530/ERC-15-0246
(C) 2015 Society for Endocrinology Printed in Great Britain
Published by Bioscientifica Ltd.
Endocrine-Related Cancer

(2015) 22, M1-M8 


\section{Introduction}

Paragangliomas (PGLs) are slow-growing hypervascular tumors arising from neural crest cell derivatives throughout the body. PGLs are closely aligned with the distribution of the autonomic nervous system and preferentially arise in the adrenal medulla, along the thoracoabdominopelvic sympathetic system, or in parasympathetic paraganglia that are mainly located in the head and neck (Taieb et al. 2014a).

Approximately $30-40 \%$ of PGLs carry a germ line mutation, which frequently occurs in one of the succinate dehydrogenase (SDH) subunit genes (collectively referred to as SDHx) (Baysal et al. 2002, Neumann et al. 2009, Piccini et al. 2012, Martucci \& Pacak 2014).

The SDH complex (also named mitochondrial complex II) catalyzes the oxidation of succinate to fumarate in the tricarboxylic acid (TCA) cycle and the respiratory chain. Deleterious mutations in any of the SDH genes (after biallelic inactivation) invariably result in decreased SDH activity, with accumulation of succinate, which acts as an oncometabolite (Selak et al. 2005).

We, and others, have recently shown that ex vivo metabolomics studies are very reliable methods for classifying various pheochromocytomas (PHEOs)/PGLs according to their genetic background (Imperiale et al. 2013a, Richter et al. 2014, Rao et al. 2015). Assessment of succinate concentration and succinate:fumarate ratio can be clinically relevant for discriminating $S D H x$-related tumors from sporadic and other hereditary PHEOs/PGLs (Lendvai et al. 2014, Richter et al. 2014, Imperiale et al. 2015a). These studies nicely pointed toward the importance of metabolite profiling in the evaluation of these tumors.

In recent years, anatomic and functional imaging techniques have gained an increasing role in the characterization of PHEOs/PGLs (Taieb et al. 2013, 2014a). The use of magnetic resonance imaging (MRI) as a non-ionizing technique is rapidly growing in the evaluation of PGLs with clinical implementation of multiparametric sequences that provide relevant biological information (i.e., diffusion weighted imaging, dynamic contrast enhancement, and spectroscopy). MR spectroscopy (MRS) enables quantification of metabolites in tissues (Bruhn etal. 1989, King et al. 2010). MRS uses intrinsic MR proprieties of some atomic nuclei (i.e., ${ }^{1}$ Hydrogen, ${ }^{31}$ Phosphorous, ${ }^{19}$ Fluorine, and ${ }^{13}$ Carbon) placed in a radiofrequency range of magnetic fields (de Graaf 2008). Proton spectroscopy $\left({ }^{1} \mathrm{H}\right.$-MRS) is available in numerous magnetic field strengths (currently from 1.5 to 7 Tesla) and has been evaluated in the characterization of various brain (Fellah et al. 2013) and extracerebral tumors (King et al. 2005, Jansen et al. 2012, Abdel Razek \& Poptani 2013).

Currently, there is a strong interest in i) assessing the genetic and metabolomics backgrounds of tumors based on their metabolomics profile using noninvasive techniques that would not require obtaining additional tumor samples (in some patients, especially those with metastatic PHEO/PGL, it is difficult to obtain because biopsy may be contraindicated); ii) decreasing radiation exposure of cancer patients to the repeated use of anatomical and functional modalities in assessing or monitoring therapeutic responses; iii) minimizing the cost to a patient as well as the health care system by using multiple imaging modalities; and iv) selecting appropriate treatment options that are expected in the near future to be largely based on the assessment of tumor metabolomics profiles because metabolites are now considered as 'first-line' combat soldiers in a cancer cell.

Thus, the aim of the present study was to evaluate the potential role of 3T proton MRS in identifying various $S D H x$-related PGLs and then to compare those results to other sporadic PGLs or non-PGL tumors.

\section{Materials and methods}

\section{Patients}

Eight consecutive patients with suspicion of either HNPGL or a neck nerve sheath tumor were evaluated by ${ }^{1} \mathrm{H}$-MRS in addition to conventional MR sequences. PGL patients were included in a large prospective clinical trial dedicated to positron emission tomography (PET) imaging studies (NCT02186678) and were therefore evaluated by ${ }^{18} \mathrm{~F}$-FDOPA and ${ }^{68} \mathrm{Ga}$-DOTATATE PET/computed tomography (CT) (patient nos 1-6) using low-dose CT protocol. The remaining two patients gave their informed consent for use of their personal data for scientific purposes, in keeping with local institutional guidelines.

\section{MRI protocol}

MRI was performed on a 3T MR scanner (Magnetom Skyra, Siemens Healthcare, Erlangen, Germany) equipped with a 32-channel phased-array head coil. The signal of monovoxel MRS was collected following the unenhanced conventional MR sequences (for head and neck regions: $T_{1}, T_{2}$, and time of flight angiography (TOF)). The volume of interest (VOI) was carefully positioned by a radiologist with 10 years' experience (A Varoquaux). The VOI was adapted to the size

Published by Bioscientifica Ltd. 
and geometry and centered within the bulk tumor region, excluding nearby bone structures. Six outer-volume lipid suppression bands were used to suppress lipid contamination, and pre-acquisition included shimming and water suppression. Spectra were acquired with a point-resolved spectroscopy sequence (PRESS; TE, $135 \mathrm{~ms}$ and repetition time (TR), $2000 \mathrm{~ms}$ ) using the manufacturer's automated shimming procedure. An $\mathrm{H}_{2} \mathrm{O}$ signal was acquired for quantification purposes at the same location. Extra scanning time, including shimming and acquisition (120 excitations), was $8 \mathrm{~min}$.

\section{Post processing}

The MRS data were analyzed using a dedicated software described elsewhere (Le Fur et al. 2010). After Fourier transformation, the residual water signal was removed using HLSVD (de Beer et al. 1992). Spectra was fitted using HRQUEST (Ratiney et al. 2005) with a simulated database that incorporated seven metabolites selected according to the HRMAS spectrum (Imperiale et al. 2013a,b, 2015a): acetate, alanine, glutamate, glutathione, lactate, methionine, and succinate.

Quality of the spectra were classified as follows: i) good: thin resonances, good water suppression, and absence of lipid signal contamination; ii) medium: broad resonances but clearly distinguishable, acceptable water suppression, and low lipid contamination; iii) poor: resonances hardly distinguishable and/or bad water suppression and/or high lipid signal; and iv) uninterpretable spectrum. MRS spectra were interpreted by experts blinded to the SDH mutation status and pathological findings.

\section{HRMAS MRS}

HRMAS MRS was performed in three cases (carotid body PGL (CBP) from patient nos 3 and 4 and one abdominal extra-adrenal PGL from patient no. 1) from the analysis of a frozen intact tumor sample of about $15 \mathrm{mg}$. Spectra were acquired on a Bruker Avance III 500 Spectrometer (500.13 MHz) (Bruker BioSpin, Wissembourg, France). One-dimensional (1D) proton and two-dimensional (2D) heteronuclear $\left({ }^{1} \mathrm{H}_{-}{ }^{13} \mathrm{C}\right)$ experiments were recorded. Selected metabolites were quantified according to our previous reports (Imperiale et al. 2013b).

\section{Gold standard}

Pathological analysis of the tumor was considered the gold standard for final diagnosis. When surgery was not indicated or already performed, lesions were characterized as PGL by tumor positivity on either ${ }^{18} \mathrm{~F}$-FDOPA or ${ }^{68} \mathrm{Ga}$-DOTATATE in specific locations, regardless of genetic background.

\section{Results}

\section{Patients and tumors}

Eight patients (two males and six females, age 30-73 years) were included in the present study (Table 1). Final diagnoses included six PGLs, one cervical schwannoma, and one cervical neurofibroma. Pathological confirmation was obtained in two PGL and two benign nerve sheath tumors. In other PGLs, the diagnosis was based on findings

Table 1 Patient and tumor characteristics, and imaging findings

\begin{tabular}{|c|c|c|c|c|c|}
\hline Patient & Diagnosis & Status & Focality & $\begin{array}{l}\text { Location } \\
\text { of the } \\
\text { tumor } \\
\text { assessed } \\
\text { by MRS }\end{array}$ & ${ }^{18}$ F-FDOPA ${ }^{a}$ \\
\hline 1 & PGL & $S D H D$ & Multi & Vagal & + \\
\hline 2 & PGL & $S D H D$ & Multi & Jugular & + \\
\hline 3 & PGL & $S D H B$ & Uni & $\begin{array}{c}\text { Carotid } \\
\text { body }\end{array}$ & + \\
\hline 4 & PGL & $S D H D$ & Multi & $\begin{array}{c}\text { Carotid } \\
\text { body }\end{array}$ & + \\
\hline 5 & PGL & Sporadic & Uni & Jugular & + \\
\hline 6 & PGL & Sporadic & Uni & Jugular & + \\
\hline 7 & Neurofibroma & - & Uni & Vagal & ND \\
\hline 8 & Schwannoma & - & Uni & Vagal & ND \\
\hline
\end{tabular}

\begin{tabular}{c} 
\\
${ }^{68}$ Ga- \\
DOTATATE \\
\hline+ \\
+ \\
+ \\
+ \\
+ \\
+ \\
ND \\
ND \\
\hline
\end{tabular}

\begin{tabular}{|c|c|c|c|}
\hline $\begin{array}{c}\text { Tumor } \\
\text { volume } \\
\left(\mathrm{cm}^{3}\right)^{\mathrm{b}}\end{array}$ & $\begin{array}{l}\text { Gold } \\
\text { standard }\end{array}$ & $\begin{array}{l}\text { Spectra } \\
\text { quality }\end{array}$ & Succinate \\
\hline 8.2 & Pathology & Good & Detected \\
\hline 2.3 & PET imaging & Medium & Detected \\
\hline 19.6 & PET imaging & Good & Detected \\
\hline 4.4 & Pathology & $\begin{array}{l}\text { Uninter- } \\
\text { pretable }\end{array}$ & NA \\
\hline 2.1 & PET imaging & Poor & Not detected \\
\hline 1.5 & PET imaging & Poor & Not detected \\
\hline 24.9 & Pathology & Good & Not detected \\
\hline 6.7 & Pathology & Medium & Not detected \\
\hline
\end{tabular}

ND, not done.

${ }^{a}{ }^{18} \mathrm{~F}$-FDOPA and ${ }^{68} \mathrm{Ga}$-DOTATATE findings in PGLs evaluated by MRS.

${ }^{\mathrm{b}}$ Tumor volumes were measured on contrast-enhanced T1-weighted MR images using OsiriX Software (v5.6, 64 bit, Geneva, Switzerland).

http://erc.endocrinology-journals.org DOI: 10.1530/ERC-15-0246
(C) 2015 Society for Endocrinology Printed in Great Britain
Published by Bioscientifica Ltd 
A

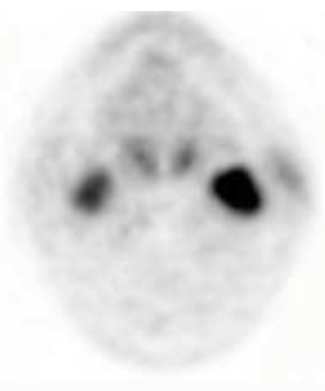

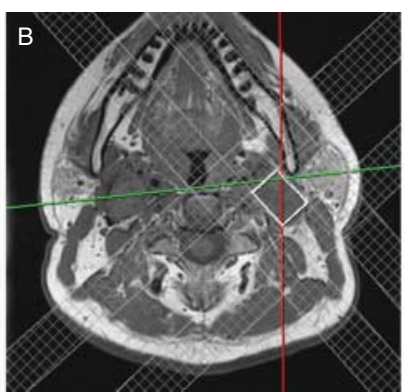

Figure 1

Multifocal SDHD-related PGLs (patient no. 1). (A) Axial ${ }^{68} \mathrm{Ga}$-DOTATATE PET showing bilateral vagal PGL. (B) Axial plane of pre-acquisition VOI adaptation before ${ }^{1} \mathrm{H}$-MRS PRESS, with manual placement of six saturation bands (only four visible on image) to avoid lipid contamination from the parapharyngeal space and spine. (C) The acquired spectrum, fitted spectrum, fitted macromolecules, and residue (i.e., the acquired spectrum minus the result of the fit) represented from top to bottom. The last line shows the succinate signal as found by the quantification algorithm.

from images using various specific tracers. Genetic testing was performed in all but one PGL and revealed SDHD mutations in three cases (patient nos 1,2, and 4) and $S D H B$ in one case (patient no. 3). Tumors evaluated by MRS were localized to the jugular foramen in three cases, the retrostyloid parapharyngeal space in three cases, and the carotid body in two cases. Mean tumor volume was $8.7 \mathrm{ml}$ and ranged from 1.5 to $24.9 \mathrm{ml}$.

\section{MRS findings}

Spectra quality was considered good in three cases, medium in two, poor in two, and uninterpretable in the latter case due to motion artifacts. Smaller lesions had lower spectra quality compared to larger lesions. Jugular
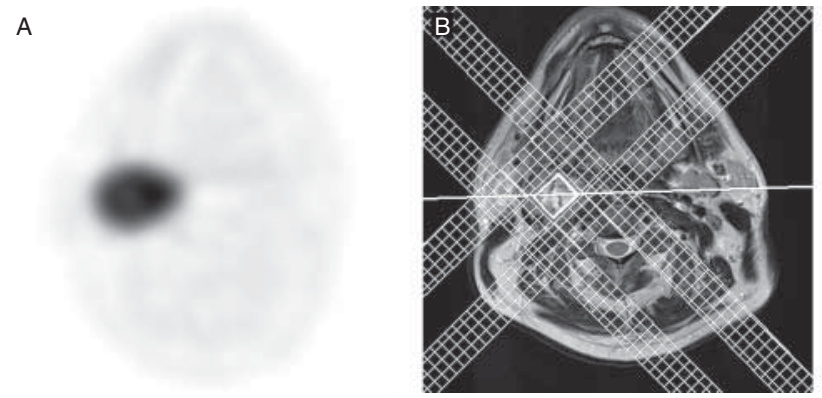

C org/10.1530/ERC-15-0246. given at the end of this article).

\section{Discussion}

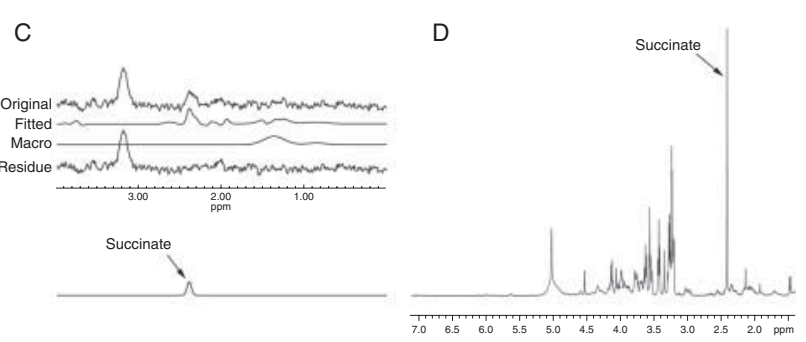

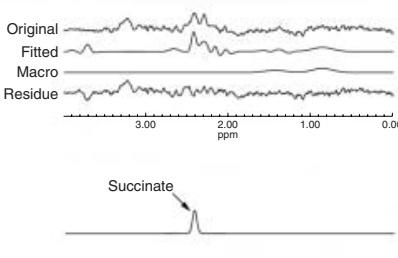

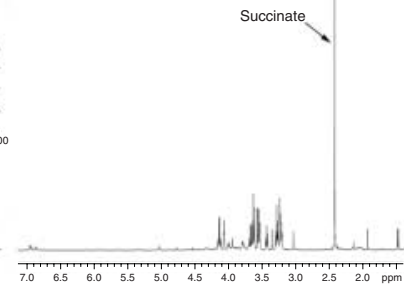

Other resonances are not shown for reason of clarity. It can be seen on the residue that some signals are still visible. The metabolite(s) giving these signals are still not assigned and therefore not present in the database. (D) ${ }^{1} \mathrm{H}$-HRMAS MR spectra obtained from the analysis of an abdominal PGL from this patient showing an obvious peak of succinate (singlet at 2.41 p.p.m.). A full colour version of this figure is available at http://dx.doi.

PGL also exhibited a poorer spectra quality compared to vagal PGL and CBP. A succinate resonance peak was only detected in $S D H x$-related tumor patients. Succinate was detected in patient no. 3, who had a $2.3 \mathrm{ml}$ jugular PGL with medium quality spectra. Two examples of ${ }^{1} \mathrm{H}-\mathrm{MR}$ spectra in comparison to HRMAS findings are presented in Figs 1 and 2. A spectra without succinate is shown in Supplementary Fig. 1 (see section on supplementary data

The present study demonstrates that ${ }^{1} \mathrm{H}$-MRS could enable in vivo detection of succinate in $S D H x$-related tumors. These results emphasize that, beyond its localization

Figure 2

Carotid body SDHB-related PGL (patient no. 3). (A) Axial ${ }^{18}$ F-FDOPA PET showing a highly avid CBP. (B) VOI adaptation before ${ }^{1} \mathrm{H}-\mathrm{MRS}$ with manual placement of six saturation bands (only four visible on image). (C) The last line shows the succinate signal as found by the quantification algorithm.

(D) ${ }^{1}$ H-HRMAS MR spectra obtained from the analysis of the CBP showing an important accumulation of succinate in tumoral tissue (singlet at 2.41 p.p.m.). 
value, this imaging modality provides unique opportunities for better characterizing these tumors at a metabolomic level that is uniquely linked to their molecular signature, in these as well as other tumors. Thus, recently, it has been proposed that ex vivo detection of succinate and other metabolites could guide genetic testing (Lendvai et al. 2014, Richter et al. 2014). In recent years, it has also been demonstrated that immunohistochemistry using specific antibodies against SDH subunits is a reliable method for predicting $S D H$ mutations (van Nederveen et al. 2009). However, these and other ex vivo techniques have some limitations because they are not applicable in cases where PGLs are treated by repeated radiation, cannot be removed surgically due to their unusual location or size, and are unable to provide continuous specific metabolite assessment that would be very useful for monitoring or predicting changes in intratumoral metabolism, tumor aggressiveness, resistant or responsive therapy, and metastatic spread. Therefore, in vivo metabolomics characterization of any tumor is becoming of paramount interest for guiding genetic, therapeutic, and outcome evaluation of cancer patients.

Metabolomics or metabolite profiling is the youngest sibling in the family of -omics fields and is growing up. Maturing right behind genomics, transcriptomics, and proteomics, metabolomics is the comprehensive analysis of small molecule metabolites (Reitman et al. 2011). Succinate is a component of the TCA cycle that serves as an electron donor to complex II. Succinate is present in the brain at $\sim 0.5 \mathrm{mmol} / \mathrm{kg}$ (Klunk et al. 1996). Although present at such a low concentration, it contains four protons from two methylene groups that all contribute to a singlet at 2.39 p.p.m. In conventional in vivo 1D MRS experiments, this signal overlaps with resonances of glutamate and glutamine (Govindaraju et al. 2000). However, using HRMSAS, we have previously shown that $S D H x$-associated PGL exhibits a very low glutamate content (Imperiale et al. $2015 a$ ). Increased succinate has also been reported in human brain abscesses (Shukla-Dave et al. 2001).

Pioneering studies or hypotheses from investigations by Selak et al. (2005) showed the accumulation of succinate in $S D H x$-tumors. Elevated plasma succinate has even been proposed as a screening test for detecting $S D H x$ mutationpositive individuals (Hobert et al. 2012). Detection of succinate has been also found to be very useful for classifying SDH variants of unknown etiology as pathogenic or depicting SDH deficiency without an SDHx mutation such as an SDH promoter methylation that may occur in some cases like Carney triad (Haller et al. 2014, Imperiale et al. 2015a). More recently, a significantly increased succinate:fumarate ratio has also been described in $S D H x$-related PGLs and proposed as a new metabolic marker of these tumors (Lendvai et al. 2014, Richter et al. 2014). Several studies have shown that succinate and possibly other metabolites, the so-called PHEO/PGL metabolomics milieu, play important and perhaps the most crucial role in the pathogenesis, behavior, and outcome of these tumors (Vicha et al. 2014). Thus, beyond SDHx mutations, disruption of the TCA cycle has been described for other mutations that predispose to PHEOs/PGLs such as isocitrate dehydrogenase type 1 (Gaal et al. 2010), fumarate hydratase (Castro-Vega et al. 2014), and the more recently described malate dehydrogenase type 2 (Cascon et al. 2015). It is also expected that the detection of other TCA enzyme mutations may play an important role in the pathogenesis of PHEO/PGL, and the use of metabolomics to uncover new PHEO/PGL-specific metabolomic profiles will become crucial in novel discoveries of such mutations in the very near future.

High MRS spectra quality, demonstrated by the ability to separate resonances from important metabolites within the tumor, depends on various technical aspects such as voxel and pre-saturation band placement, pre-acquisition shimming quality, acquisition parameters, water and fat suppression, and post processing. Compared to the brain, the MRS of HNPGLs is challenging due to their anatomical location near or within bone structures and the surrounding adipose tissue, which create susceptibility artifacts and make the shimming process very difficult. Furthermore, data quality is also degraded by patient motion (head movement) and vascular pulsatility. In the present study, jugular PGL and small lesions exhibited a poorer spectra quality compared to other sites. These PGLs, which arise from the dome of the jugular vein and are located in the temporal bone, are more sensitive to susceptibility artifacts, with specific problems for optimizing shimming and fat suppression. In one CBP, motion artifacts lead to an uninterpretable spectrum. A manual shimming procedure could improve spectral quality but requires longer examinations.

In our study, smaller lesions were also found to have lower quality spectra. In these cases, the lower size of the voxel volume decreased the signal-to-noise ratio (SNR). It is possible to reduce the voxel size to $1 \mathrm{ml}$ (Abdel Razek \& Poptani 2013), but this requires increasing the number of excitations with a subsequent increased duration of the scan.

The present and previous studies open and strengthen a new field of in vivo metabolomics profiling in various PHEOs/PGLs. In recent years, ${ }^{18} \mathrm{~F}$-FDG uptake has also been

Published by Bioscientifica Ltd. 
shown to be strongly dependent on patient genotype. Thus, the degree of ${ }^{18} \mathrm{~F}$-FDG uptake has also been proposed as a predictor of SDHx PHEOs/PGLs (Taieb et al. 2009, 2014b, Timmers et al. 2012, Blanchet et al. 2014). According to this lesion-based model using SUV ratio and tumor diameter, sensitivity, specificity, positive predictive value, negative predictive value, and accuracy were 80.8 , 63.6, 83.1, 60.0, and 75.5\% respectively (Blanchet et al. 2014). Beyond the practical constraints associated with MRS, it is anticipated that in vivo detection of succinate would have a better pneumococcal polysaccharide vaccination than ${ }^{18} \mathrm{~F}$-FDG uptake, but this remains to be tested on a very large population of patients with different genetic backgrounds.

It is also expected that MRS could be applied to the metabolite assessment in the setting of adrenal and extraadrenal sympathetic PGLs. Even if compared to jugular foramen localization, the ${ }^{1} \mathrm{H}$-MRS analysis of the adrenal region encounters less susceptibility artefacts (dental fillings, petrous apex pneumatisation), the physiologic respiratory motion complicates matters. Faria et al. (2007) showed that adrenal ${ }^{1} \mathrm{H}$-MRS free breathing point-resolved multi-voxel acquisition enabled adenomas and PHEOs to be distinguished from carcinomas and metastases using a ratio between choline, creatine, and lipids. Most authors recommend the use of respiratory triggering, which, in return, needs elaborate and time-consuming post-processing processes to exploit the spectra (Schwarz \& Leach 2000, Katz-Brull et al. 2003, Faria et al. 2007, Kim et al. 2009). Recently, Imperiale et al. (2015b) have confirmed that respiratory-triggered single-voxel ${ }^{1} \mathrm{H}$-MRS enables in vivo detection of catecholamines in PHEOs. We believe that assessing succinate in the adrenal masses of $S D H x$ patients will require respiratory-triggered single-voxel ${ }^{1} \mathrm{H}$-MRS acquisitions with repeated excitations, improving the sensibility for succinate detection to the detriment of the examination length.

Several studies have pointed well towards impairments in oxidative phosphorylation processes within PHEOs/PGLs (Favier et al. 2009, Vicha et al. 2014, Rao et al. 2015). Phosphorus metabolism (inorganic phosphate, phospho-creatine, ATP) can be evaluated in vivo by ${ }^{31}$ P-MRS (Abdel Razek \& Poptani 2013) and, therefore, should provide new information in the metabolomic/energy characterization of these tumors. The use of hyperpolarized nuclei may also be an attractive additional tool for proton MRS because it may increase the signal factor by 6000 and quality spectra (increased SNR). Therefore, this enables for in vivo assessment of small tumors in a faster acquisition time
(Kurhanewicz et al. 2011). Hyperpolarized succinate can be produced using para-hydrogen induced polarization and was thus used as a contrast agent for MRI and MRS in preclinical studies of brain tumors (Bhattacharya et al. 2007). More recently, it has been shown that hyperpolarized $\left({ }^{2} \mathrm{H},{ }^{13} \mathrm{C}\right)$-labeled glucose by dynamic nuclear polarization increases the SNR up to 10000 times (Ardenkjaer-Larsen et al. 2003). This contrast agent could be used for the assessment of succinate and other TCA metabolites by MRS (Mishkovsky et al. 2012) and successfully applied to various hereditary PHEO/PGL that are considered as a metabolic disease.

In conclusion, in vivo metabolomics analysis may serve as an important bridge between molecular genetics and imaging. ${ }^{1} \mathrm{H}$-MRS could be added to the classical MR sequences for characterization of various PHEOs/PGLs, especially those related to TCA cycle impairment. Imperiale et al. (2015b) have also recently shown that ${ }^{1} \mathrm{H}$-MRS enables in vivo detection of catecholamines in PHEOs. The recently introduced PET/MR systems enable acquisition of MRS and PET data during a single examination, provide high-quality fusion of both modalities and potentially provide the opportunity to perform multi-voxel acquisition analysis in the setting of prospective studies.

In vivo detection of succinate shows promise in further guiding genetic testing and characterization of SDH variants, especially in the absence of available tumor samples and detection of changes in plasma succinate levels in these patients, which is currently insufficient. This approach also has the future potential of serving as an important tool for monitoring therapeutic responses while avoiding excessive radiation exposure or functional imaging techniques that are often very costly yet limited in availability. Nevertheless, the conclusions of the present study should be tested on a very large population of patients with $S D H x$ and non-SDHx tumors.

Supplementary data

This is linked to the online version of the paper at http://dx.doi.org/10.1530/ ERC-15-0246

Declaration of interest

The authors declare that there is no conflict of interest that could be perceived as prejudicing the impartiality of the research reported.

\section{Funding}

This research did not receive any specific grant from any funding agency in the public, commercial or not-for-profit sector.

Published by Bioscientifica Ltd. 


\section{References}

Abdel Razek AA \& Poptani H 2013 MR spectroscopy of head and neck cancer. European Journal of Radiology 82 982-989. (doi:10.1016/j.ejrad. 2013.01.025)

Ardenkjaer-Larsen JH, Fridlund B, Gram A, Hansson G, Hansson L, Lerche MH, Servin R, Thaning M \& Golman K 2003 Increase in signal-to-noise ratio of $>10,000$ times in liquid-state NMR. PNAS $\mathbf{1 0 0} 10158-10163$. (doi:10.1073/pnas.1733835100)

Baysal BE, Willett-BrozickJE, Lawrence EC, Drovdlic CM, Savul SA, McLeod DR, Yee HA, Brackmann DE, Slattery WH III, Myers EN et al. 2002 Prevalence of SDHB, SDHC, and SDHD germline mutations in clinic patients with head and neck paragangliomas. Journal of Medical Genetics 39 178-183. (doi:10.1136/jmg.39.3.178)

de Beer R, van den Boogaart A, van Ormondt D, Pijnappel WW, den Hollander JA, Marien AJ \& Luyten PR 1992 Application of time-domain fitting in the quantification of in vivo ${ }^{1} \mathrm{H}$ spectroscopic imaging data sets. NMR in Biomedicine 5 171-178. (doi:10.1002/nbm.1940050403)

Bhattacharya P, Chekmenev EY, Perman WH, Harris KC, Lin AP, Norton VA, Tan CT, Ross BD \& Weitekamp DP 2007 Towards hyperpolarized (13)C-succinate imaging of brain cancer. Journal of Magnetic Resonance 186 150-155. (doi:10.1016/j.jmr.2007.01.017)

Blanchet EM, Gabriel S, Martucci V, Fakhry N, Chen CC, Deveze A, Millo C, Barlier A, Pertuit M, Loundou A et al. $2014{ }^{18}$ F-FDG PET/CT as a predictor of hereditary head and neck paragangliomas. European Journal of Clinical Investigation 44 325-332. (doi:10.1111/eci.12239)

Bruhn H, Frahm J, Gyngell ML, Merboldt KD, Hanicke W, Sauter R \& Hamburger C 1989 Noninvasive differentiation of tumors with use of localized H-1 MR spectroscopy in vivo: initial experience in patients with cerebral tumors. Radiology 172 541-548. (doi:10.1148/radiology. 172.2.2748837)

Cascon A, Comino-Mendez I, Curras-Freixes M, de Cubas AA, Contreras L, Richter S, Peitzsch M, Mancikova V, Inglada-Perez L, Perez-Barrios A et al. 2015 Whole-exome sequencing identifies $\mathrm{MDH} 2$ as a new familial paraganglioma gene. Journal of the National Cancer Institute $\mathbf{1 0 7}$ article djv053. (doi:10.1093/jnci/djv053)

Castro-Vega LJ, Buffet A, De Cubas AA, Cascon A, Menara M, Khalifa E, Amar L, Azriel S, Bourdeau I, Chabre O et al. 2014 Germline mutations in $\mathrm{FH}$ confer predisposition to malignant pheochromocytomas and paragangliomas. Human Molecular Genetics 23 2440-2446. (doi:10.1093/hmg/ddt639)

Faria JF, Goldman SM, Szejnfeld J, Melo H, Kater C, Kenney P, Huayllas MP, Demarchi G, Francisco VV, Andreoni C et al. 2007 Adrenal masses: characterization with in vivo proton MR spectroscopy - initial experience. Radiology 245 788-797. (doi:10.1148/radiol.2453061854)

Favier J, Briere JJ, Burnichon N, Riviere J, Vescovo L, Benit P, Giscos-Douriez I, De Reynies A, Bertherat J, Badoual C et al. 2009 The Warburg effect is genetically determined in inherited pheochromocytomas. PLOS ONE 4 e7094. (doi:10.1371/journal.pone.0007094)

Fellah S, Caudal D, De Paula AM, Dory-Lautrec P, Figarella-Branger D, Chinot O, Metellus P, Cozzone PJ, Confort-Gouny S, Ghattas B et al. 2013 Multimodal MR imaging (diffusion, perfusion, and spectroscopy): is it possible to distinguish oligodendroglial tumor grade and $1 p / 19 q$ codeletion in the pretherapeutic diagnosis? AJNR. American Journal of Neuroradiology 34 1326-1333. (doi:10.3174/ajnr.A3352)

Gaal J, Burnichon N, Korpershoek E, Roncelin I, Bertherat J, Plouin PF, de Krijger RR, Gimenez-Roqueplo AP \& Dinjens WN 2010 Isocitrate dehydrogenase mutations are rare in pheochromocytomas and paragangliomas. Journal of Clinical Endocrinology and Metabolism 95 1274-1278. (doi:10.1210/jc.2009-2170)

Govindaraju V, Young K \& Maudsley AA 2000 Proton NMR chemical shifts and coupling constants for brain metabolites. NMR in Biomedicine $\mathbf{1 3}$ 129-153. (doi:10.1002/1099-1492(200005)13:3<129::AID-NBM619> 3.0.CO;2-V) de Graaf RA 2008 In Vivo NMR Spectroscopy: Principles and Techniques. Second Edition. Chichester, West Sussex, UK: John Wiley.

Haller F, Moskalev EA, Faucz FR, Barthelmess S, Wiemann S, Bieg M, Assie G, Bertherat J, Schaefer IM, Otto C et al. 2014 Aberrant DNA hypermethylation of SDHC: a novel mechanism of tumor development in Carney triad. Endocrine-Related Cancer 21 567-577. (doi:10.1530/ ERC-14-0254)

Hobert JA, Mester JL, Moline J \& Eng C 2012 Elevated plasma succinate in PTEN, SDHB, and SDHD mutation-positive individuals. Genetics in Medicine 14 616-619. (doi:10.1038/gim.2011.63)

Imperiale A, Moussallieh FM, Sebag F, Brunaud L, Barlier A, Elbayed K, Bachellier P, Goichot B, Pacak K, Namer IJ et al. 2013a A new specific succinate-glutamate metabolomic hallmark in SDHx-related paragangliomas. PLoS ONE 8 e80539. (doi:10.1371/journal.pone.0080539)

Imperiale A, Elbayed K, Moussallieh FM, Reix N, Piotto M, Bellocq JP, Goichot B, Bachellier P \& Namer IJ 2013b Metabolomic profile of the adrenal gland: from physiology to pathological conditions. EndocrineRelated Cancer 20 705-716. (doi:10.1530/ERC-13-0232)

Imperiale A, Moussallieh FM, Roche P, Battini S, Cicek AE, Sebag F, Brunaud L, Barlier A, Elbayed K, Loundou A et al. 2015a Metabolome profiling by HRMAS NMR spectroscopy of pheochromocytomas and paragangliomas detects SDH deficiency: clinical and pathophysiological implications. Neoplasia 17 55-65. (doi:10.1016/j.neo.2014.10.010)

Imperiale A, Battini S, Averous G, Mutter D, Goichot B, Bachellier P, Pacak K, Taieb D \& Namer IJ 2015b In vivo detection of catecholamines by magnetic resonance spectroscopy: a potential specific biomarker for pheochromocytoma diagnosis. Surgery [in press]. (doi:10.1016/j.surg.2015.03.012)

Jansen JF, Schoder H, Lee NY, Stambuk HE, Wang Y, Fury MG, Patel SG, Pfister DG, Shah JP, Koutcher JA et al. 2012 Tumor metabolism and perfusion in head and neck squamous cell carcinoma: pretreatment multimodality imaging with ${ }^{1} \mathrm{H}$ magnetic resonance spectroscopy, dynamic contrast-enhanced MRI, and $\left[{ }^{18}\right.$ F]FDG-PET. International Journal of Radiation Oncology, Biology, Physics 82 299-307. (doi:10.1016/ j.ijrobp.2010.11.022)

Katz-Brull R, Rofsky NM \& Lenkinski RE 2003 Breathhold abdominal and thoracic proton MR spectroscopy at 3T. Magnetic Resonance in Medicine 50 461-467. (doi:10.1002/mrm.10560)

Kim S, Salibi N, Hardie AD, Xu J, Lim RP, Lee VS \& Taouli B 2009 Characterization of adrenal pheochromocytoma using respiratorytriggered proton MR spectroscopy: initial experience. AJR. American Journal of Roentgenology 192 450-454. (doi:10.2214/AJR.07.4027)

King AD, Yeung DK, Ahuja AT, Tse GM, Yuen HY, Wong KT \& van Hasselt AC 2005 Salivary gland tumors at in vivo proton MR spectroscopy. Radiology 237 563-569. (doi:10.1148/radiol.2372041309)

King AD, Yeung DK, Yu KH, Mo FK, Hu CW, Bhatia KS, Tse GM, Vlantis AC, Wong JK \& Ahuja AT 2010 Monitoring of treatment response after chemoradiotherapy for head and neck cancer using in vivo ${ }^{1} \mathrm{H} \mathrm{MR}$ spectroscopy. European Radiology 20 165-172. (doi:10.1007/s00330009-1531-2)

Klunk WE, Xu C, Panchalingam K, McClure RJ \& Pettegrew JW 1996 Quantitative ${ }^{1} \mathrm{H}$ and ${ }^{31} \mathrm{P}$ MRS of PCA extracts of postmortem Alzheimer's disease brain. Neurobiology of Aging 17 349-357. (doi:10.1016/0197-4580(96)00035-8)

Kurhanewicz J, Vigneron DB, Brindle K, Chekmenev EY, Comment A, Cunningham CH, Deberardinis RJ, Green GG, Leach MO, Rajan SS et al. 2011 Analysis of cancer metabolism by imaging hyperpolarized nuclei: prospects for translation to clinical research. Neoplasia 13 81-97. (doi:10.1593/neo.101102)

Le Fur Y, Nicoli F, Guye M, Confort-Gouny S, Cozzone PJ \& Kober F 2010 Grid-free interactive and automated data processing for MR chemical shift imaging data. Magma 23 23-30. (doi:10.1007/s10334-009-0186-y)

Lendvai N, Pawlosky R, Bullova P, Eisenhofer G, Patocs A, Veech RL \& Pacak K 2014 Succinate-to-fumarate ratio as a new metabolic marker to detect the presence of SDHB/D-related paraganglioma: initial experimental and ex vivo findings. Endocrinology 155 27-32. (doi:10.1210/en. 2013-1549) 
Martucci VL \& Pacak K 2014 Pheochromocytoma and paraganglioma: diagnosis, genetics, management, and treatment. Current Problems in Cancer 38 7-41. (doi:10.1016/j.currproblcancer.2014.01.001)

Mishkovsky M, Comment A \& Gruetter R 2012 In vivo detection of brain Krebs cycle intermediate by hyperpolarized magnetic resonance. Journal of Cerebral Blood Flow and Metabolism 32 2108-2113. (doi:10.1038/jcbfm.2012.136)

van Nederveen FH, Gaal J, Favier J, Korpershoek E, Oldenburg RA, de Bruyn EM, Sleddens HF, Derkx P, Riviere J, Dannenberg H et al. 2009 An immunohistochemical procedure to detect patients with paraganglioma and phaeochromocytoma with germline SDHB, SDHC, or SDHD gene mutations: a retrospective and prospective analysis. Lancet Oncology 10 764-771. (doi:10.1016/S1470-2045(09)70164-0)

Neumann HP, Erlic Z, Boedeker CC, Rybicki LA, Robledo M, Hermsen M, Schiavi F, Falcioni M, Kwok P, Bauters C et al. 2009 Clinical predictors for germline mutations in head and neck paraganglioma patients: cost reduction strategy in genetic diagnostic process as fall-out. Cancer Research 69 3650-3656. (doi:10.1158/0008-5472.CAN-08-4057)

Piccini V, Rapizzi E, Bacca A, Di Trapani G, Pulli R, Giache V, Zampetti B, Lucci-Cordisco E, Canu L, Corsini E et al. 2012 Head and neck paragangliomas: genetic spectrum and clinical variability in 79 consecutive patients. Endocrine-Related Cancer 19 149-155. (doi:10.1530/ERC-11-0369)

Rao JU, Engelke UF, Sweep FC, Pacak K, Kusters B, Goudswaard AG, Hermus AR, Mensenkamp AR, Eisenhofer G, Qin N et al. 2015 Genotype-specific differences in the tumor metabolite profile of pheochromocytoma and paraganglioma using untargeted and targeted metabolomics. Journal of Clinical Endocrinology and Metabolism 100 E214-E222. (doi:10.1210/jc.2014-2138)

Ratiney H, Sdika M, Coenradie Y, Cavassila S, van Ormondt D \& Graveron-Demilly D 2005 Time-domain semi-parametric estimation based on a metabolite basis set. NMR in Biomedicine 18 1-13. (doi:10.1002/nbm.895)

Reitman ZJ, Jin G, Karoly ED, Spasojevic I, Yang J, Kinzler KW, He Y, Bigner DD, Vogelstein B \& Yan H 2011 Profiling the effects of isocitrate dehydrogenase 1 and 2 mutations on the cellular metabolome. PNAS 108 3270-3275. (doi:10.1073/pnas.1019393108)

Richter S, Peitzsch M, Rapizzi E, Lenders JW, Qin N, de Cubas AA, Schiavi F, Rao JU, Beuschlein F, Quinkler M et al. 2014 Krebs cycle metabolite profiling for identification and stratification of pheochromocytomas/ paragangliomas due to succinate dehydrogenase deficiency. Journal of
Clinical Endocrinology and Metabolism 99 3903-3911. (doi:10.1210/ jc.2014-2151)

Schwarz AJ \& Leach MO 2000 Implications of respiratory motion for the quantification of 2D MR spectroscopic imaging data in the abdomen. Physics in Medicine and Biology 45 2105-2116. (doi:10.1088/0031-9155/ 45/8/304)

Selak MA, Armour SM, MacKenzie ED, Boulahbel H, Watson DG, Mansfield KD, Pan Y, Simon MC, Thompson CB \& Gottlieb E 2005 Succinate links TCA cycle dysfunction to oncogenesis by inhibiting HIF- $\alpha$ prolyl hydroxylase. Cancer Cell 7 77-85. (doi:10.1016/j.ccr.2004.11.022)

Shukla-Dave A, Gupta RK, Roy R, Husain N, Paul L, Venkatesh SK, Rashid MR, Chhabra DK \& Husain M 2001 Prospective evaluation of in vivo proton MR spectroscopy in differentiation of similar appearing intracranial cystic lesions. Magnetic Resonance Imaging 19 103-110. (doi:10.1016/ S0730-725X(01)00224-7)

Taieb D, Sebag F, Barlier A, Tessonnier L, Palazzo FF, Morange I, Niccoli-Sire P, Fakhry N, De Micco C, Cammilleri S et al. $2009{ }^{18}$ F-FDG avidity of pheochromocytomas and paragangliomas: a new molecular imaging signature? Journal of Nuclear Medicine 50 711-717. (doi:10.2967/jnumed.108.060731)

Taieb D, Varoquaux A, Chen CC \& Pacak K 2013 Current and future trends in the anatomical and functional imaging of head and neck paragangliomas. Seminars in Nuclear Medicine 43 462-473. (doi:10.1053/ j.semnuclmed.2013.06.005)

Taieb D, Kaliski A, Boedeker CC, Martucci V, Fojo T, Adler JR Jr \& Pacak K $2014 a$ Current approaches and recent developments in the management of head and neck paragangliomas. Endocrine Reviews 35 795-819. (doi:10.1210/er.2014-1026)

Taieb D, Timmers HJ, Shulkin BL \& Pacak K 2014b Renaissance of (18)F-FDG positron emission tomography in the imaging of pheochromocytoma/paraganglioma. Journal of Clinical Endocrinology and Metabolism 99 2337-2339. (doi:10.1210/jc.2014-1048)

Timmers HJ, Chen CC, Carrasquillo JA, Whatley M, Ling A, Eisenhofer G, King KS, Rao JU, Wesley RA, Adams KT et al. 2012 Staging and functional characterization of pheochromocytoma and paraganglioma by ${ }^{18} \mathrm{~F}$-fluorodeoxyglucose $\left({ }^{18} \mathrm{~F}\right.$-FDG) positron emission tomography. Journal of the National Cancer Institute 104 700-708. (doi:10.1093/ jnci/djs188)

Vicha A, Taieb D \& Pacak K 2014 Current views on cell metabolism in SDHx-related pheochromocytoma and paraganglioma. Endocrine-Related Cancer 21 R261-R277. (doi:10.1530/ERC-13-0398)

Received in final form 17 June 2015

Accepted 23 June 2015

Made available online as an Accepted Preprint

25 June 2015
(C) 2015 Society for Endocrinology Printed in Great Britain 